\title{
Avaliação do Perfil Higiênico-Sanitário de Restaurantes Comerciais do Município de Botucatu- Sp: Equipamentos, Utensílios e Mãos de Manipuladores de Alimentos.
}

Daniela Martinelli Xavier (I), Priscilla Camilla Zucco dos Santos (I), Ricardo Seiti Yamatogi (I), José Carlos de Figueiredo Pantoja1 (I),

Fábio Sossai Possebon (I), André Vicente Ruiz de Matos (I), Eduardo Delbon Baldini (I), Lilian Michaloski (I), José Paes de Almeida Nogueira Pinto (I), Germano Francisco Biondi (I)

(I) UNESP - Universidade Estadual Paulista (Distrito de Rubião Junior, s/n )

\section{Resumo}

Com a transição do comportamento social imposta pelo ritmo acelerado do dia-a-dia, incentivou-se o crescimento do mercado de food service. Paralelamente ao crescimento do setor observou-se uma maior preocupação com a ocorrência de Doenças Transmitidas por Alimentos, que frequentemente são associadas ao uso de serviços de alimentação. Este trabalho avaliou o perfil higiênico-sanitário de 35 restaurantes situados no município de Botucatu-SP, através de análises microbiológicas de 272 amostras entre utensílios (facas, raladores e superfícies de corte), equipamentos (liquidificadores) e mãos de manipuladores de alimentos, antes (momento A) e após a higienização (momento D) das mesmas. Foram investigadas a presença de Listeria monocytogenes e enumeração de microorganismos mesófilos, coliformes à $35^{\circ} \mathrm{C}$ e Escherichia coli em todas as amostras. Contagens de Staphylococcus coagulase positiva (SCP) foram realizadas somente nas amostras de mãos. Todas as amostras foram negativas para L. monocytogenes. Das 134 amostras de mãos (67 no momento A e 67 no momento D), SCP foi detectado em 7 amostras (5,2\%). Em relação à presença de mesófilos em utensílios, 91,4\% (n=32) das facas

\footnotetext{
Referência:

Daniela Martinelli Xavier, Priscilla Camilla Zucco dos Santos, Ricardo Seiti Yamatogi, José Carlos de Figueiredo Pantoja1, Fábio Sossai Possebon, André Vicente Ruiz de Matos, Eduardo Delbon Baldini, Lilian Michaloski, José Paes de Almeida Nogueira Pinto, Germano Francisco Biondi. Avaliação do Perfil Higiênico-Sanitário de Restaurantes Comerciais do Município de Botucatu-Sp: Equipamentos, Utensílios e Mãos de Manipuladores de Alimentos.. In: Anais do $12^{\circ}$ Congresso Latinoamericano de Microbiologia e Higiene de Alimentos - MICROAL 2014 [= Blucher Food Science Proceedings, num.1, vol.1]. São Paulo: Editora Blucher, 2014. DOI 10.5151/foodsci-microal-179
} 
estavam contaminadas, $82,4 \%(\mathrm{n}=28)$ dos raladores e $94,3 \%(\mathrm{n}=33)$ das superfícies; ainda, $100 \%(\mathrm{n}=34)$ dos liquidificadores e $100 \%(\mathrm{n}=134)$ das amostras de mãos estavam contaminados. Para a contagem de coliformes à $35^{\circ} \mathrm{C}$, dentre os utensílios analisados, $57,1 \%(\mathrm{n}=20)$ das facas estavam contaminadas; $38,2 \%(n=13)$ dos raladores e $62,8 \%(n=22)$ das superfícies; nos equipamentos, $97 \%(n=33)$; das 67 amostras de mãos analisadas somente do momento A, 73,1\% (n=49) apresentaram contaminação, enquanto que no momento $\mathrm{D}$, a contaminação foi presente em $62,7 \%$ $(\mathrm{n}=42)$. Quanto à presença de E. coli em utensílios, 8,6\% $(\mathrm{n}=3)$ das facas analisadas estavam contaminadas, $2,9 \%(\mathrm{n}=1)$ dos raladores e $8,6 \%(\mathrm{n}=3)$ das superfícies; 8,8\% (n=3) dos liquidificadores; 2 (3\%) amostras de mãos analisadas no momento A estavam contaminadas, enquanto que no momento D, 1 amostra (1,5\%) foi positiva. As altas percentagens de contaminação por micro-organismos mesófilos e coliformes à $35^{\circ} \mathrm{C}$ e em menor escala por patógenos na maioria dos equipamentos, utensílios e mãos dos manipuladores, reforçam a necessidade de adoção de medidas mais eficientes de higienização, treinamento e supervisão constantes em todas as linhas de preparo do alimento.

Palavras-Chave: análises microbiológicas, contaminação, restaurantes Agência de Fomento: 